\title{
Characteristics Analysis of Multiphase Flow in Annulus in Natural Gas Hydrate Reservoir Drilling
}

\author{
Na Wei ${ }^{1,}$ a , Wan-Tong Sun ${ }^{1, b^{*}}$, Yong-Jie Li ${ }^{1}$, Ying-Feng Meng ${ }^{1}$, Gao Li ${ }^{1}$, Ping \\ Guo ${ }^{1}$, An-Qi Liu ${ }^{2}$ \\ ${ }^{1}$ State Key Laboratory of Oil and Gas Geology and Exploration and Natural gas hydrate \\ collaborative innovation center, Southwest Petroleum University, Chengdu, China \\ ${ }^{2}$ Geological Explorations and Development Institute, Chuan Qing Drilling Engineering Company \\ Limited, Chengdu, China \\ aweina8081@163.com, ${ }^{\mathrm{b}} 1403543721 @ q q . c o m$ \\ ${ }^{*}$ corresponding author
}

Keywords: hydrate; decomposition; multiphase flow; characteristics analysis

Abstract. During the process of natural gas hydrate drilling, hydrate cuttings will decompose at a certain position, which promotes the formation of complex multiphase flow in annulus. Aiming at this, dynamic model of hydrate mass transfer decomposition is established considering temperature and pressure. On the basis of this, multiphase flow coupling model is got under gas-liquid-solid complex media with non-equilibrium phase transformation during natural gas hydrate drilling. Finally, numerical simulation method is used to analyze critical point for hydrate decomposition and variation laws of multiphase flow in annulus under different operation parameters. The result shows that high delivery rate and density of drilling mud will restrain decomposition of hydrate, and high rate of penetration will promote that, which provides important theoretical basis for downhole safety control.

\section{Introduction}

With the development of deepwater drilling, downhole safety control while drilling to natural gas hydrate reservoir almost has been an inevitable problem. As is shown in Fig. 1, during hydrate drilling, hydrate cuttings will decompose at a certain position, leading to characteristic parameters of multiphase flow significantly transforming. On the basis of this, dynamic model of hydrate mass transfer decomposition and multiphase flow coupling model are established under gas-liquid-solid complex media with non-equilibrium phase transformation. Then critical point for hydrate decomposition and variation laws of multiphase flow in annulus are analyzed under different operation parameters.

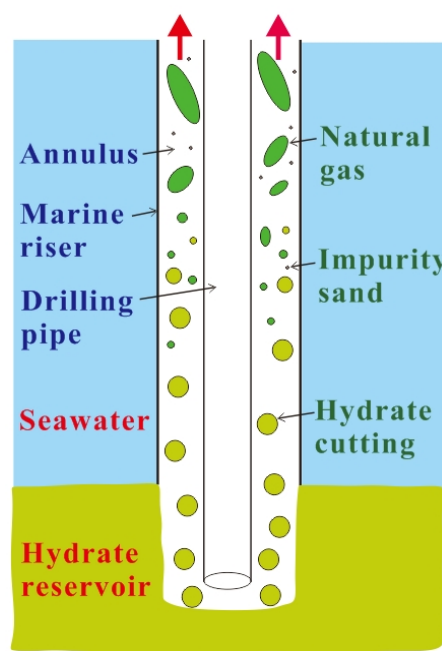

Fig. 1 Wellbore flow during marine hydrate drilling Fig. 2 Model of hydrate decomposition 


\section{Decomposition Model of Natural Gas Hydrate}

Some assumptions are made: 1) natural gas hydrate cuttings are ideal round particles; 2) natural gas hydrate is pure methane hydrate; 3) there is full heat exchange between pipe flow in annulus and seawater. As is shown in Fig. 2, the decomposition of natural gas hydrate is divided into two parts, chemical reaction on interface and mass transfer of gaseous product.

The chemical reaction rate on interface and mass transfer rate of gaseous product are written as

$$
\begin{aligned}
& r_{c}=k_{c} S_{i}\left(C_{e q}-C^{*}\right), \\
& r_{t}=k_{f} S_{i}\left(C^{*}-C_{g}^{v}\right) .
\end{aligned}
$$

In Eq. 1 and Eq.2, $r_{c}$ is the chemical reaction rate on interface, mol/s; $r_{t}$ is the mass transfer rate of gaseous methane, mol/s; $\mathrm{k}_{\mathrm{c}}$ is the reaction rate constant on interface[1], $\mathrm{m} / \mathrm{s} ; \mathrm{k}_{\mathrm{f}}$ is mass transfer coefficient, $\mathrm{m} / \mathrm{s} ; \mathrm{C}^{*}$ is the gas concentration of methane at reaction interface of hydrate, $\mathrm{mol} / \mathrm{m}^{3} ; \mathrm{C}_{\mathrm{g}}^{\mathrm{v}}$ is the gas concentration of methane in gas phase, $\mathrm{mol} / \mathrm{m}^{3} ; \mathrm{C}_{\mathrm{eq}}$ is the gas concentration of methane at the condition of three-phase equilibria[2], $\mathrm{mol} / \mathrm{m}^{3}$.

According to assumption of quasi-stable state reaction[3], $r_{g}=r_{c}=r_{t}$, decomposition rate of hydrate is written as

$$
r_{g}=\frac{\left(C_{e q}-C_{g}^{v}\right)}{1 / k_{f}+1 / k_{c}} S_{i} .
$$

With the equation of $\mathrm{C}=\mathrm{n} / \mathrm{V}$ and the natural gas compressibility state equation of $\mathrm{Pv}=\mathrm{ZnRT}$, it can be got that

$$
C_{g}^{v}-C_{e q}=\frac{p_{t}-p_{e q}}{Z R T_{t}}
$$

In Eq.4, $\mathrm{p}_{\mathrm{eq}}$ is pressure at the condition of three-phase equilibria, $\mathrm{Pa} ; \mathrm{p}_{\mathrm{t}}$ is ambient pressure at a certain time, $\mathrm{Pa} ; \mathrm{T}_{\mathrm{t}}$ is the temperature of water, $\mathrm{K}$. Considering full heat exchange between pipe flow in annulus and seawater, temperature in annulus is equal to that of seawater $\left(T_{t}=T_{w}\right)$ [4].

The consumption rate of natural gas hydrate is written as

$$
r_{g}=-\frac{d n}{d t}=-\frac{d}{d t}\left(\frac{\rho_{s} \cdot 4 \pi r^{3} / 3}{M_{s}}\right)=-S_{i} \frac{\rho_{s}}{M_{s}} \frac{d r}{d t} .
$$

In Eq.5, $S_{i}$ is the surface area of hydrate particle, $\mathrm{m}^{2}, \mathrm{~S}_{\mathrm{i}}=4 \pi \mathrm{r}^{2} ; \rho_{\mathrm{s}}$ is density of natural gas hydrate, $\mathrm{kg} / \mathrm{m}^{3} ; \mathbf{M}_{\mathrm{s}}$ is molar mass of natural gas hydrate, $\mathrm{kg} / \mathrm{mol} ; \mathrm{r}$ is particle radius of natural gas hydrate, $\mathrm{m} ; \mathrm{t}$ is reaction time, $\mathrm{s}$. The initial condition is $\mathrm{r}_{\mathrm{t}=0}=\mathrm{r}_{0}$, where $\mathrm{r}_{0}$ is initial radius, $\mathrm{m}$. Combining Eq. 3 and Eq.5 gives the equation of hydrate decomposition model

$$
\frac{d r}{d t}=\frac{\left(C_{g}^{v}-C_{e q}\right)}{1 / k_{f}+1 / k_{c}} \frac{M_{s}}{\rho_{s}} .
$$

The Models to Predict Characteristic Parameters of Multiphase Flow with Complex Media in Annulus during Marine Natural Gas Hydrate Reservoir Drilling

The mass conservation equations of gas phase and liquid phase[5,6] are written as

$$
\frac{\partial}{\partial t}\left(A \rho_{g} E_{g}\right)+\frac{\partial}{\partial Z}\left(A \rho_{g} E_{g} V_{g}\right)=q_{g}
$$




$$
\frac{\partial}{\partial t}\left(A \rho_{l} E_{l}\right)+\frac{\partial}{\partial Z}\left(A \rho_{l} E_{l} V_{l}\right)=q_{l} \text {. }
$$

The momentum conservation equation of gas-liquid-solid mixture[7] is written as

$$
\begin{aligned}
& \frac{\partial}{\partial t}\left(\rho_{l} V_{l} E_{l}+\rho_{g} V_{g} E_{g}+\rho_{s} V_{s} E_{s}\right)+\frac{\partial}{\partial Z}\left(p+\rho_{l} V_{l}^{2} E_{l}+\rho_{g} V_{g}^{2} E_{g}+\rho_{s} V_{s}^{2} E_{s}\right) \\
& +\left(\rho_{l} E_{l}+\rho_{g} E_{g}+\rho_{s} E_{s}\right) g \sin \alpha+\frac{\lambda \rho_{m} V_{m}^{2}}{2 d}=0
\end{aligned}
$$

In Eq.7 to Eq.9, $\rho_{\mathrm{g}}, \rho_{\mathrm{l}}, \rho_{\mathrm{s}}, \rho_{\mathrm{m}}$ are densities of gas, liquid, solid and mixed phase, $\mathrm{kg} / \mathrm{m}^{3} ; \mathrm{V}_{\mathrm{g}}, \mathrm{V}_{\mathrm{l}}, \mathrm{V}_{\mathrm{s}}$ are migration velocities of gas, liquid and solid phase, $\mathrm{m} / \mathrm{s} ; \mathrm{E}_{\mathrm{g}}, \mathrm{E}_{\mathrm{l}}, \mathrm{E}_{\mathrm{s}}$ are contents of gas, liquid and solid phase, nondimension; $\mathrm{q}_{\mathrm{g}}, \mathrm{q}_{\mathrm{l}}, \mathrm{q}_{\mathrm{s}}$ are quality variation rates of gas, liquid and solid phase in unit length, $\mathrm{kg} /(\mathrm{s} \cdot \mathrm{m}) ; \lambda$ is friction coefficient, nondimension; $\mathrm{d}$ is the diameter of pipe, $\mathrm{m}$.

\section{The Analysis through Numerical Simulation}

Some fundamental parameters are assumed that seawater depth is $1000 \mathrm{~m}$; well depth is $1200 \mathrm{~m}$; core interval of hydrate reservoir is $50 \mathrm{~m}$; filling factor of hydrate is $75 \%$; diameter of marine riser and casing is $0.508 \mathrm{~m}$; bit diameter is $0.445 \mathrm{~m}$; diameter of drilling pipe is $0.127 \mathrm{~m}$.

The Influence on Multiphase Flow in Annulus by Delivery Rate of Mud Pump. As is shown in Fig. 3, critical point for hydrate decomposition and variation laws of multiphase flow in annulus are calculated with rate of penetration at $10 \mathrm{~m} / \mathrm{h}$, density of drilling mud at $1.03 \mathrm{~g} / \mathrm{m}^{3}$, delivery rate of mud pump at 201/s and 401/s.
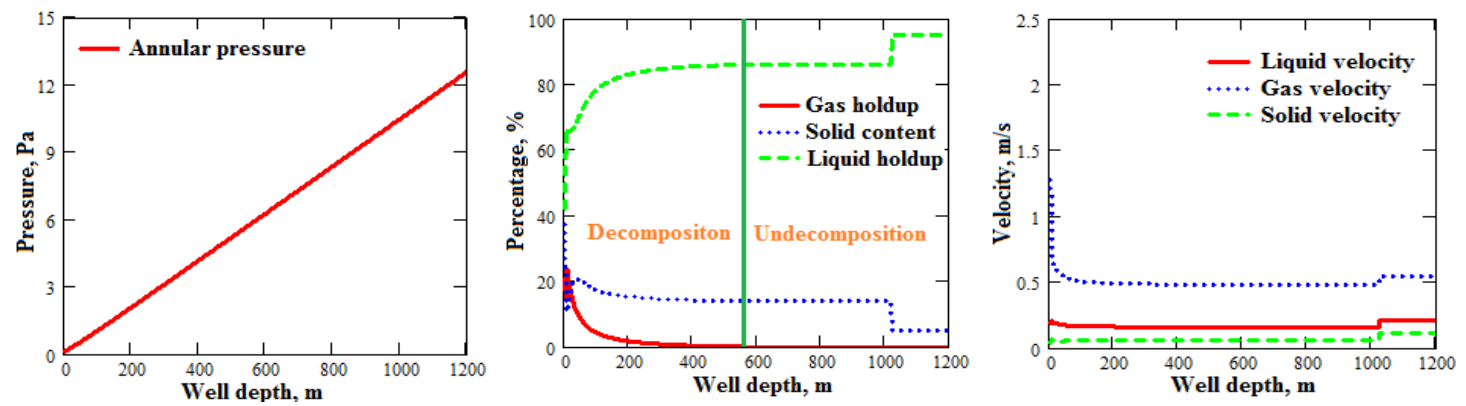

a) Flow parameters in annulus with delivery rate of mud pump at 201/s
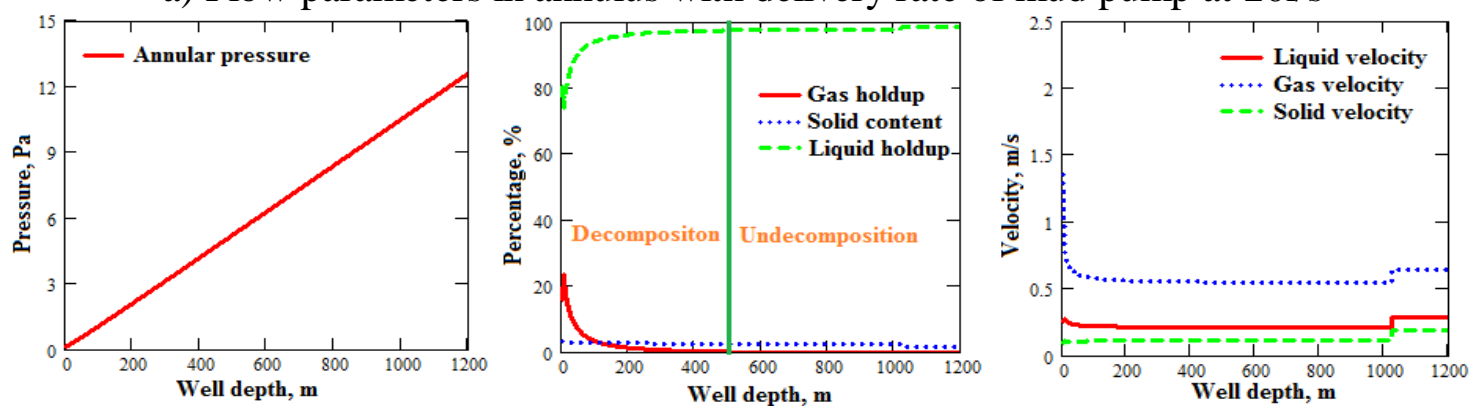

b) Flow parameters in annulus with delivery rate of mud pump at $401 / \mathrm{s}$

Fig. 3 Flow parameters in annulus with different delivery rate of mud pump

As is shown in Fig. 3, critical point for hydrate decomposition rises from $550 \mathrm{~m}$ to $500 \mathrm{~m}$ of well depth when delivery rate of mud pump rises from 201/s to 401/s. Critical point for hydrate decomposition goes up with increasing delivery rate because of the slightly rising wellbore pressure in annulus and full heat exchange between pipe flow in annulus and seawater. It also can be seen from Fig. 3 that when delivery rate of mud pump becomes higher, gas holdup in top hole and solid content in wellbore will decrease. Besides, cuttings carrying capacity of drilling mud increases for the faster annulus velocity.

The Influence on Multiphase Flow in Annulus by Rate of Penetrate. As is shown in Fig. 4, critical point for hydrate decomposition and variation laws of multiphase flow in annulus are calculated with density of drilling mud at $1.03 \mathrm{~g} / \mathrm{m}^{3}$, delivery rate of mud pump at $301 / \mathrm{s}$, rate of penetration at 
$10 \mathrm{~m} / \mathrm{h}$ and $30 \mathrm{~m} / \mathrm{h}$.
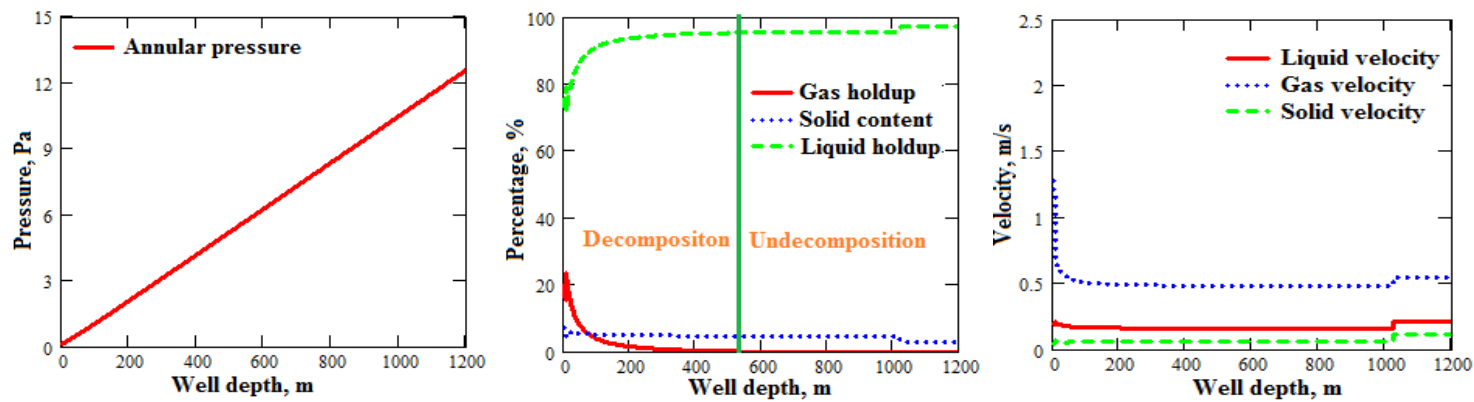

a) Flow parameters in annulus with rate of penetration at $10 \mathrm{~m} / \mathrm{h}$
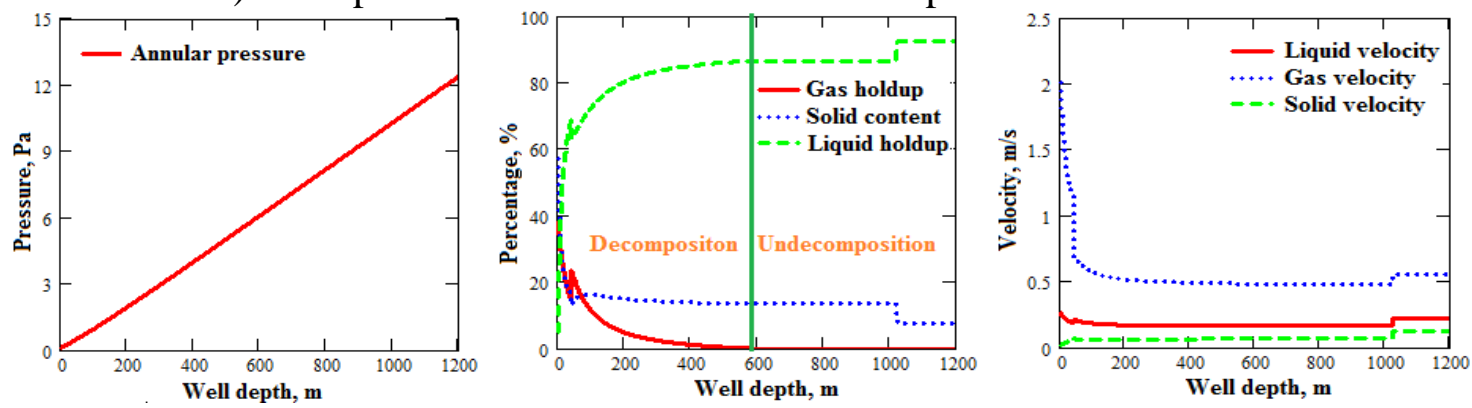

b) Flow parameters in annulus with rate of penetration at $30 \mathrm{~m} / \mathrm{h}$

Fig. 4 Flow parameters in annulus with different rate of penetration

As is shown in Fig. 4, critical point for hydrate decomposition drops from 520m to 590m of well depth when rate of penetration rises from $10 \mathrm{~m} / \mathrm{h}$ to $30 \mathrm{~m} / \mathrm{h}$. When rate of penetration becomes higher, more hydrate cuttings will rise along with drilling mud in annulus per unit time. Then more natural gas will be separated from hydrate cutting in upward process, which can lead to degressive pressure in annulus and lower critical point for hydrate decomposition. At the same time, gas holdup and gas velocity in annular in top hole and solid content in wellbore increase obviously. Something could be done like enhancing delivery rate to ensure safety control in wellbore. It also will be noticed that the curve of gas holdup has a sharp point of inflection at wellbore depth of $50 \mathrm{~m}$ for flow pattern transforming.

The Influence on Multiphase Flow in Annulus by Density of Drilling Mud. As is shown in Fig. 5 , critical point for hydrate decomposition and variation laws of multiphase flow in annulus are calculated with delivery rate of mud pump at $301 / \mathrm{s}$, rate of penetration at $20 \mathrm{~m} / \mathrm{h}$, density of drilling mud at $1.03 \mathrm{~g} / \mathrm{m}^{3}$ and $1.23 \mathrm{~g} / \mathrm{m}^{3}$.
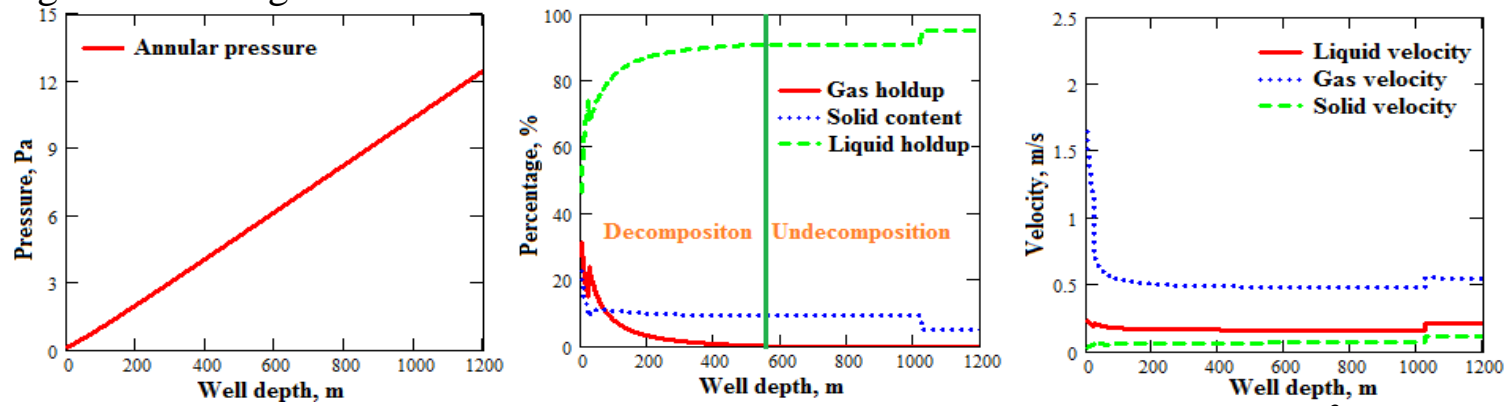

a) Flow parameters in annulus with density of drilling mud at $1.03 \mathrm{~g} / \mathrm{m}^{3}$ 

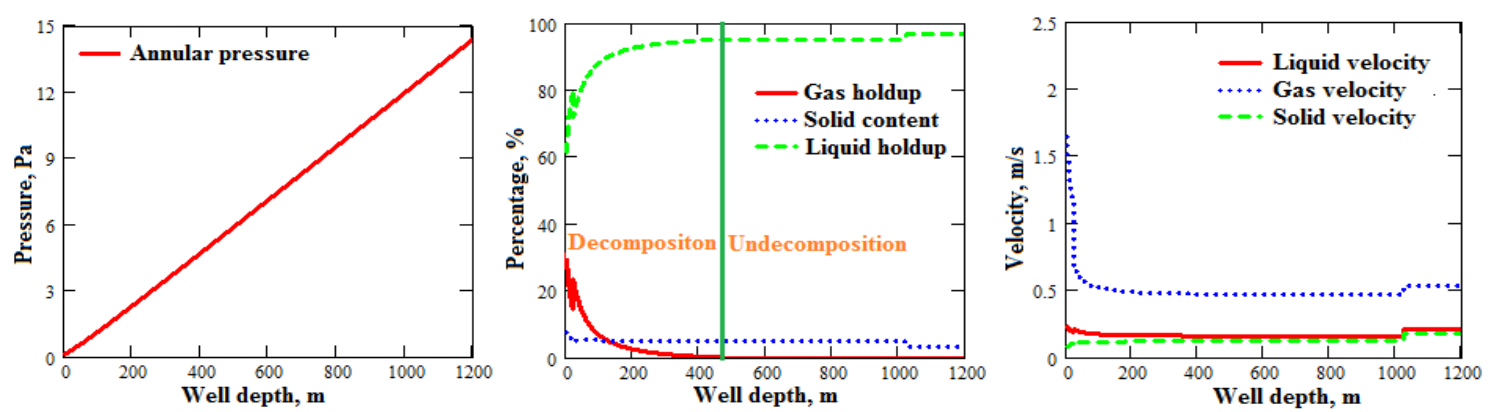

b) Flow parameters in annulus with density of drilling mud at $1.23 \mathrm{~g} / \mathrm{m}^{3}$

Fig. 5 Flow parameters in annulus with different density of drilling mud

It can be seen from Fig. 5 that when density of drilling mud is enhanced from $1.03 \mathrm{~g} / \mathrm{m}^{3}$ to $1.23 \mathrm{~g} / \mathrm{m}^{3}$, critical point for hydrate decomposition rises from $565 \mathrm{~m}$ to $500 \mathrm{~m}$ of well depth. Critical point for hydrate decomposition will go up with higher density of drilling mud for higher wellbore pressure in annulus. At the same time, solid content in wellbore will decrease with increasing density of drilling mud, and the solid velocity in annulus becomes faster which shows that cuttings carrying capacity of drilling mud has increased.

\section{Conclusions}

(1) With increasing delivery rate of mud pump, wellbore pressure in annulus slightly rises. Gas holdup in top hole and solid content in wellbore will decrease, and annulus velocity and cuttings carrying capacity of drilling mud will increase. Critical point for hydrate decomposition goes up considering full heat exchange between pipe flow in annulus and seawater.

(2) The natural gas hydrate decomposition will be promoted by lower pressure in annulus for increasing rate of penetration. Gas holdup and gas velocity in annular in top hole and solid content in wellbore will increase obviously when rate of penetration becomes higher.

(3)The pressure in wellbore will be enhanced by increasing density of drilling mud, which will restrain decomposition of natural gas hydrate. When density of drilling mud increases, solid content in wellbore will decrease and cuttings carrying capacity of drilling mud will increase with a faster solid velocity in annulus.

\section{Acknowledgements}

Open Fund of State Key Laboratory of Oil and Gas Geology and Exploration, SWPU (Grant no.PLN1309, no.PLN1418); National Natural Science Funds of China (Grant no. 51204140, L1322021, 51334003).

\section{References}

[1] H. C. Kim, et al. Kinetics of methane hydrate decomposition, Chem. Eng. Sci. 42(1987)1645-1653.

[2] Changyu Sun, Guangjin Chen. Methane hydrate dissociation above $0^{\circ} \mathrm{C}$ and below $0^{\circ} \mathrm{C}$, Fluid. Phase. Equilibr. 242(2006)123-128.

[3] Xiaoxia He, Jinsong Yu, et al. Particle Shrinking Dynamic Model for Methane Hydrate Decomposition, Natural Gas Geoscience. 16(2005)819-821. (In Chinese)

[4] J. Romero, E. Touboul. Temperature prediction for deepwater wells: a field validated methodology, SPE 49056. (1998).

[5] Na Wei. The Continuous Liquid Lifting Experiment for the Gas Well with High Gas-liquid Ratio, The American Institute of Physics(AIP). (2011). (In Chinese)

[6] Na Wei, Yingfeng Meng, et al. Transient Flow Characteristics of Gas Lift in Underbalanced Drilling, Acta Petrolei Sinica. 3(2014)166-171. (In Chinese)

[7] Na Wei. The Study on Entire Process of Underbalanced Drilling Flow Model, Chengdu: Southwest Petroleum University. (2007). (In Chinese) 